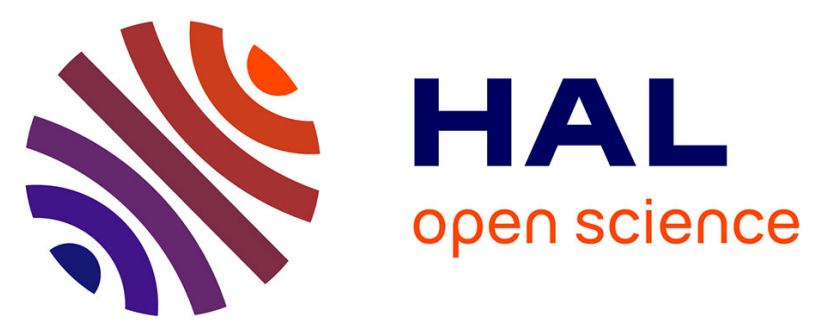

\title{
Paper strengthening by polyaminoalkylalkoxysilane copolymer networks applied by spray or immersion: a model study
}

Camille Piovesan, Anne-Laurence Dupont, Isabelle Fabre-Francke, Odile Fichet, Bertrand Lavédrine, Hervé Cheradame

\section{To cite this version:}

Camille Piovesan, Anne-Laurence Dupont, Isabelle Fabre-Francke, Odile Fichet, Bertrand Lavédrine, et al.. Paper strengthening by polyaminoalkylalkoxysilane copolymer networks applied by spray or immersion: a model study. Cellulose, 2014, 21, pp.705-715. 10.1007/s10570-013-0151-9 . hal-01491042

\section{HAL Id: hal-01491042 \\ https://hal.science/hal-01491042}

Submitted on 22 Mar 2017

HAL is a multi-disciplinary open access archive for the deposit and dissemination of scientific research documents, whether they are published or not. The documents may come from teaching and research institutions in France or abroad, or from public or private research centers.
L'archive ouverte pluridisciplinaire HAL, est destinée au dépôt et à la diffusion de documents scientifiques de niveau recherche, publiés ou non, émanant des établissements d'enseignement et de recherche français ou étrangers, des laboratoires publics ou privés. 


\title{
Paper strengthening by polyaminoalkylalkoxysilane copolymer networks applied by spray or immersion: a model study
}

\author{
Camille Piovesan • Anne-Laurence Dupont • \\ Isabelle Fabre-Francke • Odile Fichet • \\ Bertrand Lavédrine $\cdot$ Hervé Chéradame
}

Received: 26 September 2013/Accepted: 17 December 2013/Published online: 25 December 2013

(C) Springer Science+Business Media Dordrecht 2013

\begin{abstract}
Two di-alkoxysilanes, with (AMDES, aminopropylmethyldiethoxysilane) or without (DMDES, dimethyldiethoxysilane) an amine function, and a trialkoxy aminosilane (APTES, aminopropyltriethoxysilane) as well as their mixtures were introduced in paper as fiber strengthening agents. The polymerization and copolymerization of these polysiloxanes in the paper were investigated. In all the cases where APTES was present, the formation of networks was established by measuring the soluble fraction amount extracted from the treated papers. A slight decrease of the opacity of the paper sheets when AMDES was part of the treatment
\end{abstract}

Electronic supplementary material The online version of this article (doi:10.1007/s10570-013-0151-9) contains supplementary material, which is available to authorized users.

C. Piovesan · A.-L. Dupont $(\bowtie) \cdot$ B. Lavédrine Centre de Recherche sur la Conservation des Collections, Muséum National d'Histoire Naturelle, CNRS-USR 3224, 36 rue Geoffroy-Saint-Hilaire, 75005 Paris, France e-mail: aldupont@mnhn.fr

C. Piovesan · I. Fabre-Francke · O. Fichet Laboratoire de Physico-Chimie des Polymères et des Interfaces (LPPI, EA 2528), Institut des Matériaux, Université de Cergy-Pontoise, 5 mail Gay Lussac, Neuville sur Oise, 95031 Cergy-Pontoise Cedex, France

H. Chéradame

Laboratoire Analyse et Modélisation pour la Biologie et l'Environnement, CNRS UMR 8587, Université d'Évry Val-d'Essonne, Boulevard François Mitterrand, 91025 Évry, France was noted. The presence of APTES reduced this opacity loss. The study of the physicochemical properties of the treated paper (mechanical strength and alkalinity) demonstrated that, besides the required deacidification feature, the different treatments allowed an efficient strengthening of the cellulose fibers to various extents. Contact angle measurements indicated a decrease of the hydrophilic character of papers treated with the mixture APTES/AMDES and the occurrence of a hydrophobic character of the papers treated with APTES alone. These results were consistently obtained for both spray and immersion treatment processes.

Keywords Aminoalkylalkoxysilane . Copolymerization - 3D network - Cellulose . Strengthening $\cdot$ Deacidification

\section{Introduction}

The main cause of decay of paper is its acid content, which in combination with time of exposure ultimately leads to mechanical failure. Deacidification is the term used for a chemical treatment in paper conservation, which involves the neutralization of the acids in the paper and the deposition of an alkaline reserve to prevent, or at least delay, further acidification. At the mass scale (treatment of several tons of documents per year), this treatment is used as a preventive measure by libraries and archives on collections that are at risk of acidifying in the near 
future. For the already very brittle documents however, current choices are limited as no single alternative of mass treatment allows deacidifying and mechanically consolidating the paper in a single step. In particular, because of their mediocre quality, newsprint paper collections become rapidly acidic and fragile, which limits public access. The institutions are thus often hesitant to resort to mass deacidification for these collections as the process is not only cost-ineffective but simply inappropriate. A suitable treatment thus needs to be specifically designed for the long-term stabilization of very degraded paper.

The aim of the research is to develop a stabilization methodology allowing simultaneous deacidification and fiber strengthening in order to propose a novel preservation strategy for cellulosic acidic and fragile paper, especially targeting documents that are currently banned from public access. In previous publications, a multifunctional solvent phase process based on various polysiloxanes with amine functionality (aminoalkylalkoxysilanes) was studied as an alternative for libraries and archives (Ipert et al. 2005, 2006; Dupont et al. 2010; Souguir et al. 2011, 2012). Deacidification is ensured by the amine function and reinforcement is effected by in situ polymerization in the paper of the polysiloxane in ambient conditions. As opposed to current commercial mass deacidification processes (Carter 1996; Porck 1996; Baty et al. 2010), no pre-drying and no post-conditioning of the documents are needed since the water naturally contained in the paper helps the polymer in accessing the core of the fibers, and at any rate is necessary in the polymerization process (Souguir et al. 2011). Besides a clear improvement of the mechanical resistance of the paper, the treatments were shown to enhance stability toward ageing processes (Ipert et al. 2006; Dupont et al. 2010) and confer fungistatic properties to paper (Rakotonirainy et al. 2008). It was observed that depending on the type of alkoxy functionality, various strengthening effects were produced. This particular point has been the object of a thorough investigation aimed at understanding the chemical and physicochemical events occurring between cellulose macromolecules and aminoalkylalkoxysilanes, which were shown to be favored by hydrogen bonding between cellulose hydroxyl groups and the primary amine functions of the polysiloxanes (Dupont et al. 2010; Souguir et al. 2011, 2012). The results helped to interpret their effect as dry strength agents of cellulosic materials, and to tailor treatment molecules specifically adapted to papers in different conservation conditions (Souguir et al. 2011). Through threedimensional polymerization, trialkoxysilanes structures build large silicon polymer networks that considerably improve paper tensile strength (tensile modulus, breaking length), but they tend to rigidify brittle paper (lower folding endurance) (Ipert et al. 2006). On the other hand, difunctional silanes, which polymerize as linear (or cyclic) molecules efficiently confer plasticity to the paper that is moderately degraded, with medium brittleness index $(\leq 0.5)$ and measurable initial double fold endurance (Souguir et al. 2012). For very oxidized and brittle papers, with no initial double fold endurance the efficiency was much less satisfactory (Souguir et al. 2011).

Building on previous research, the present work was intended to fill in this gap by studying the consolidation of very brittle papers. The aim is to develop a treatment based on the copolymerization of polysiloxanes with different alkoxy and amine functionalities. By randomly inserting flexible linear segments into a rigid polymer network through a copolymerization of tri- and dialkoxysilanes, it should be possible to form a more flexible polymer network. This type of copolymer would thus mitigate the rigidity imposed by the incorporation of a dense network in the paper fibers, and possibly even help restructure degraded amorphous regions by more efficiently interconnecting the fibers. Polysiloxane copolymer networks with alkaline functionality were thus incorporated in paper, the chemical and physicochemical properties of which were then characterized. Upon an initial screening phase, which included an optimization of the treatment protocol, as well as alkaline reserve and opacity measurements, solidliquid extractions were carried out to characterize the quality and extent of the (co-)polymerization of the polysiloxanes in the paper. Mechanical resistance measurements (tensile modulus at break, zero-span tensile strength, double fold resistance) were then performed to assess the strengthening properties of the treatments and compare the performance of linear polysiloxanes versus homopolymer and copolymer networks. Lastly, contact angle measurements were carried out to evaluate the hydrophilic/hydrophobic character of the treated papers. Two treatment methods (immersion and spray) for impregnating the paper with the polyiloxanes were used. 


\section{Experimental}

Materials

3-aminopropylmethyldiethoxysilane (AMDES 97 \%$191 \mathrm{~g} \mathrm{~mol}^{-1}$ ), 3-aminopropyltriethoxysilane (APTES $98 \%-221 \mathrm{~g} \mathrm{~mol}^{-1}$ ), dimethyldiethoxysilane (DMD ES $97 \%-148 \mathrm{~g} \mathrm{~mol}^{-1}$ ) and hexamethyldisiloxane (HMDS $\geq 98 \%$ ) were purchased from ABCR (Gelest, France) and were used as received (liquid at room temperature).

The paper used (called P2 in the text) is made of cotton linters $(>95 \%)$ with traces of softwood pulp. It contains neither fillers nor sizing (basis weight $76 \mathrm{~g} \mathrm{~m}^{-2}$, cold extract $\mathrm{pH}$ 6.2).

\section{Polysiloxane treatment processes}

\section{Impregnation by immersion}

P2 sheets $(12 \mathrm{~cm} \times 25 \mathrm{~cm})$ were rolled into a glass hybridization tube $(35 \mathrm{~mm}$ internal diameter $\times$ $147 \mathrm{~mm}, 144 \mathrm{~mL}$ ) filled with different siloxane solutions at concentrations varying from 5 to $20 \mathrm{wt} \%$ in HMDS. These solutions contain one aminoalkylalkoxysilane (APTES or AMDES) or a mixture of two alkylalkoxysilane siloxanes with the same weight proportion [APTES/ AMDES (1:1) and APTES/DMDES (1:1)]. The treatments were carried out under constant stirring at room temperature for 15-60 min. The papers were then dried in a vacuum desiccator for $2-3 \mathrm{~h}$. They were conditioned at $23{ }^{\circ} \mathrm{C}$ and $50 \%$ relative humidity (RH) before the physico-chemical characterizations.

\section{Impregnation by surface spraying}

P2 sheets $(12 \mathrm{~cm} \times 25 \mathrm{~cm})$ were evenly sprayed on both sides with the treatment solutions using an Ecospray sprayer. The APTES/AMDES (1:1) and APTES/DMDES (1:1) solutions were mixed without solvent, directly in the sprayer reservoir (no HMDS was used). The papers were conditioned as after the immersion process.

The different treatments will be called polyAMDES, polyAPTES, polyAPTES/polyAMDES and polyAPTES/polyDMDES. In the mixtures, the concentration given in $\mathrm{wt} \%$ corresponds to the total concentration of the two compounds (i.e. $50 \%$ each).
Physicochemical measurements

The polysiloxane uptake (UP) in the paper (wt/wt\%) was measured by weighing the samples pre-conditioned at $23{ }^{\circ} \mathrm{C}$ and $50 \% \mathrm{RH}$ before and after treatment. The UP value was calculated as:

$U P(\%)=\frac{\left(w_{\text {after }}-w_{\text {before }}\right)}{w_{\text {before }}} \times 100$

where $\mathrm{w}_{\text {before }}$ and $\mathrm{w}_{\mathrm{after}}$ are the paper weights before and after treatments.

Uptake values reported in Table 2 correspond to each sheet used for each treatment, therefore no standard deviation is reported.

In order to investigate the formation of the silicone network in the paper, Soxhlet solid-liquid extractions were carried out. Papers prepared to about $80 \%$ uptake were extracted for $72 \mathrm{~h}$ with dichloromethane, which is a good solvent for polysiloxane monomers and for linear polyAMDES, and polyDMDES. After extraction, the samples were washed with acetone, dried under vacuum and then weighed. The soluble fraction (SF) (wt\%) was calculated as:

$S F(\%)=\frac{\left(w_{0}-w_{E}\right)}{w_{0}} \times 100$

where $\mathrm{W}_{0}$ and $\mathrm{W}_{\mathrm{E}}$ are the weights of the treatment before and after extraction, respectively. The soluble fractions were analyzed in $\mathrm{D}_{2} \mathrm{O}$ by ${ }^{1} \mathrm{H}$ NMR using Bruker Avance DPX250.

For the all physico-chemical properties the concentration and immersion durations selected were $7 \mathrm{wt} \%$ and $45 \mathrm{~min}$ for APTES/AMDES solution (uptake = $7 \%$ ), and $20 \mathrm{wt} \%$ and $30 \mathrm{~min}$ for APTES/DMDES solution (uptake $=8 \%$ ), respectively. Treatments with AMDES and APTES were chosen as reference for the physico-chemical properties and they were done at a concentration of $10 \mathrm{wt} \%$ in HMDS for $30 \mathrm{~min}$ as previously optimized (uptake $=6$ and $7 \%$, respectively) (Souguir et al. 2011). After treatment, papers were conditioned in a climatic room at $23{ }^{\circ} \mathrm{C}$ and $50 \%$ RH. It appears that the impregnation by spraying led to slightly higher uptakes than the impregnation by immersion, under the experimental conditions used.

Opacity measurements were performed using a hand-held spectrophotometer SP-64 (X-Rite) equipped with an integrating sphere. The configuration adopted was in reflectance mode (spectral range 400-700 $\mathrm{nm}$ in 
$10 \mathrm{~nm}$ steps), with the specular light component included, using the $5 \mathrm{~mm}$ diameter aperture. The measurement was done with the D65 Standard Illuminant and $10^{\circ}$ Standard Observer. The opacity was calculated as:

$O P(\%)=\frac{R_{0}}{R_{\infty}} \times 100$

where $R_{0}$ is the reflectance of a sample when backed with a black body and $\mathrm{R}_{\infty}$ the reflectance of the sample when backed with a white body (ceramic tile).

The alkaline reserve (AR) (meq $\left(\mathrm{OH}^{-}\right) / 100$ g paper) was determined by back-titration according to the standard method ASTM D4988-96R01. The moisture content of the papers (MC) (wt/wt\%) needed to calculate the dry mass for the alkaline reserve calculations was determined using an electronic moisture analyzer Sartorius MA150. Only average values were reported.

The zero-span tensile strength (zsTS) was measured according to TAPPI Standard T231 cm-96 using a Troubleshooter Pulmac Instrument. The value obtained (P) was transformed applying the formula zsTS = $\left(\mathrm{P}-\mathrm{P}_{0}\right) \times 0.372$ (kilogram-force $\left./ 15 \mathrm{~mm}\right)$ modified to $\left(\mathrm{P}-\mathrm{P}_{0}\right) \times 5.64\left(\right.$ daNmm $\left.^{-1}\right)$, where $\mathrm{P}_{0}=2$ (constant of the instrument). For each paper sample, zsTS was measured on ten samples. The reported zsTS values correspond to the average of all measurements with an error bar corresponding to the standard deviation.

Tensile modulus at break (MPa) was measured with an Adamel Lhomargy instrument (DY-20B), according to the standard method NF: Q03-004 July 1986, where a coaxial stress is applied to the paper sample. Samples were tested at a speed of $25 \mathrm{~mm} \cdot \mathrm{min}^{-1}$, with the $100 \mathrm{DaN}$ load cell. The data were processed with TestWorks 4 (MTS Systems Corp.) software. At least ten repeat measurements were carried out and the reported tensile moduli at break correspond to the average of all measurements with an error bar corresponding to the standard deviation.

Folding endurance (FE) (log of number of double folds) was determined with a Tinius Olsen double fold instrument, according to ISO 5626:1993. The applied force was $0.5 \mathrm{~kg}$. At least fifteen repeat measurements were carried out and the reported values correspond to the average of all measurements with an error bar corresponding to the standard deviation.

Contact angle measurements were performed using a DSA-P instrument (Kruss, Germany). One drop of water (15 $\mu \mathrm{L}-$ Millipore ultrapure) was deposited on the paper sample. The static contact angle was measured by means of a Young-Laplace drop profile fitting. After surface drying, new contact angle measurements were performed, which led to the same results thus confirming that no modification of the paper surface occurred due to the deposition of the water drop. The reported values correspond to the average of three measurements with an error bar corresponding to the standard deviation.

\section{Results and discussion}

Siloxane polymer and copolymer networks

Previous studies have shown that treatment of paper with AMDES improves the mechanical properties of cellulose fibers, and allows efficient deacidification and alkaline reserve deposition in the paper (Dupont et al. 2010; Souguir et al. 2011). The AMDES monomer is bifunctional and its hydrolysis followed by polycondensation leads to the synthesis of a linear polymer. To obtain a polymer network, a trifunctional monomer, such as APTES, must be included in the treatment mixture. APTES has been previously studied and it has been shown to deposit on the fibers surface in aggregated clumps (Souguir et al. 2011). In this work, APTES was copolymerized with bifunctional monomers in order to produce copolymer networks in the paper (Fig. 1).

The random insertion of flexible linear segments into the APTES-based polymer network was intended to mitigate the rigidity imposed by the incorporation of a dense network of pure polyAPTES, while efficient deacidification and alkaline reserve deposition would be preserved. To control the latter, DMDES and AMDES have been chosen as bifunctional monomers with which APTES is copolymerized. The copolymerization with DMDES, compound that does not bear an amine function, will induce a decrease in the deacidification and alkaline reserve deposition efficiency compared to a pure polyAPTES treatment. However, the absence of amine function may hinder the penetration of DMDES in the paper. This may be remedied by the copolymerization of DMDES with APTES. Conversely, like APTES, AMDES contains a primary amine function (Fig. 1) and the polyAPTES/ polyAMDES copolymer network should lead to the 
Fig. 1 Reaction between AMDES and APTES monomers to obtain the copolymer network

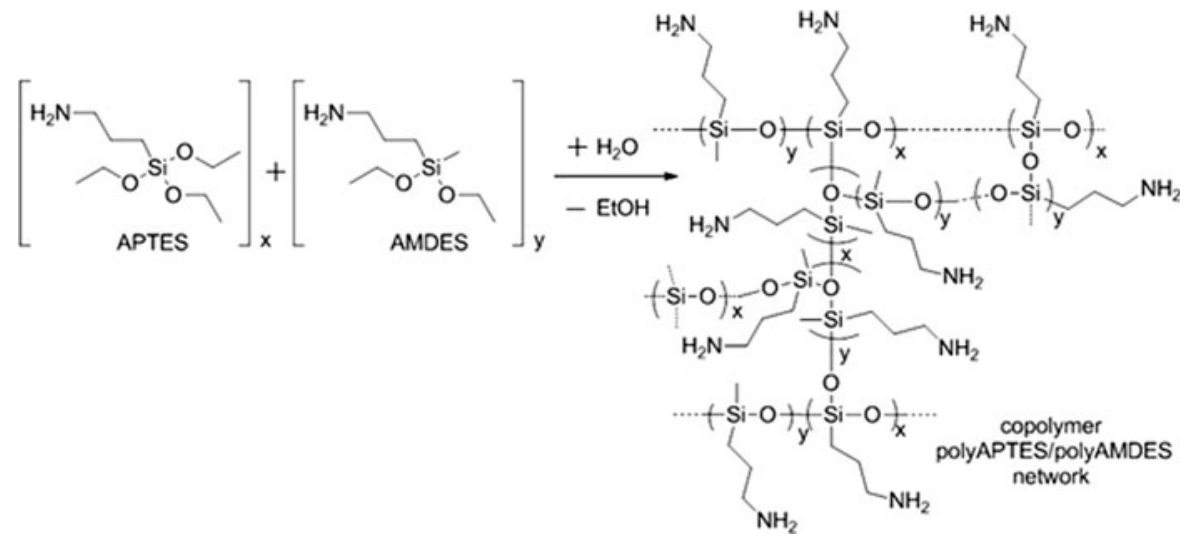

same total amine concentration than pure polyAPTES treatment, provided that the paper would absorb both networks similarly.

\section{Optimization of the treatment process}

Testing the reproducibility and optimizing the treatment process were necessary to better control the polysiloxane uptake in the paper. Exogenous compounds can be incorporated in historic paper documents in low concentrations as long as that does not modify their physical aspect or the paper basis weight too significantly. In practice, an uptake of $20 \mathrm{wt} \%$ would be the upper limit as beyond the weight increase would be considered excessive.

The impregnation of the paper by the siloxane monomers was carried out either by immersion or by spraying of the treatment solution directly on the paper surface. A polysiloxane treatment by immersion uses dilute solutions to obtain optimal uptakes. In previous publications, this treatment process was shown to be efficient (Souguir et al. 2011; Dupont et al. 2010; Souguir et al. 2012). The spraying of siloxanes directly on the paper sheets is an alternate impregnation process proposed in this work. It more easily avoids a saturation of the fibers by the treatment solution. This, on the one hand, prevents the use of large amount of reagents and solvent, and on the other hand, provides reasonable uptakes. It is also a preferred treatment option for conservation practitioners when treating books as a sprayer is easy to handle and the need of unbinding is circumvented.

The experimental conditions for obtaining comparable and reproducible results were determined. First the effect of the concentration of the immersion solution was studied. The uptake values for a $30 \mathrm{~min}$ immersion time are shown in Fig. 2A.

The uptake appears to be proportional to the solution concentration regardless of the bifunctional partner used with APTES. Moreover, at the same concentrations, the uptakes measured upon immersion in APTES/AMDES were higher than those measured with APTES/DMDES. An uptake of almost $10 \%$ was reached for $7.5 \%$ APTES/AMDES concentration, while $20 \%$ APTES/ DMDES was necessary to reach a similar uptake. This is not due to a difference in molar ratios in the $(1: 1)$ mixtures since the molar concentration of DMDES in the solutions is three times higher than that of AMDES. The explanation for this behavior is rather related to the respective chemical affinity of DMDES and AMDES for cellulose. Indeed, uptake values were very similar (Fig. 2B) when paper was immersed in either APTES or APTES/DMDES solutions at the same concentrations. Despite the presence of APTES intended to allow the copolymerization polyAPTES/polyDMDES, DMDES hardly seems to penetrate the cellulose fibers, as discussed in the next paragraph.

For a treatment to be efficient and reproducible in terms of the resulting physico-chemical properties of the paper, it is best to work at saturation conditions where small treatment duration variations will not affect the uptake value in given experimental conditions of concentration. The optimal treatment duration was determined by evaluating the time required for saturating the paper with given siloxane(s) solution(s) (plateau value). To this purpose, the papers were immersed for 15, 30, 45 and $60 \mathrm{~min}$ in the different siloxane mixtures (Fig. 3A, B).

The time required to reach the full absorption plateau was the same (45 $\mathrm{min})$ at all the APTES/AMDES 
concentrations tested. The plateau value, however, varied: concentrations of 5,7 and $10 \%$ allowed reaching uptakes of 8,11 and $20 \%$, respectively.

As shown in Fig. 3B, after 15 min immersion the uptake with the APTES/DMDES solution was constant. Figure 3B also indicates that with a concentration in siloxane monomers twice as high in the case of APTES/DMDES, the same uptake values were achieved as with half the amount of APTES/AMDES. This is also visible in Fig. 2A where similar concentrations lead to about twice the uptake value between the two mixtures. This result seems to confirm the hypothesis that DMDES does not penetrate easily into the paper, and that the uptake measured in the case of APTES/DMDES treatment is mostly that of APTES. In order to investigate this point further, a tentative uptake measurement was carried out by immersing the paper in a $10 \mathrm{wt} \%$ DMDES solution in HMDS. Because of the high volatility of both HMDS (saturation vapor pressure $=2 \mathrm{kPa}$ ) and DMDES $(3.2 \mathrm{kPa})$ compared with AMDES $(0.02 \mathrm{kPa})$ and APTES $(0.0138 \mathrm{kPa})$, weighing the treated sample could not be achieved. It is therefore likely that even if DMDES can penetrate into the paper, it will evaporate

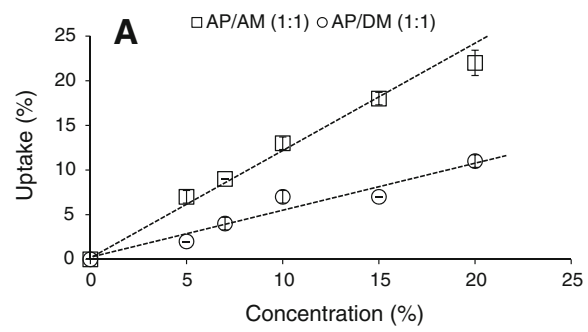

Fig. 2 Uptake as a function of A concentration of APTES/ AMDES (1:1) (AP/AM) (white square) and APTES/DMDES $(1: 1)(\mathrm{AP} / \mathrm{DM})$ (white circle) mixtures in HMDS after $30 \mathrm{~min}$

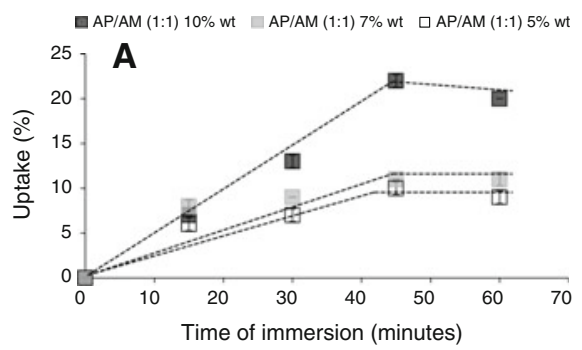

Fig. 3 Uptake as a function of immersion time in mixtures: A APTES/AMDES (AP/AM) at (white square) 5, (gray square) 7 and (black square) $10 \mathrm{wt} \%$ in HMDS; B APTES/DMDES before the reaction with APTES can even take place. This may explain why the uptakes were similar in the case of $20 \mathrm{wt} \%$ APTES/DMDES and $10 \mathrm{wt} \%$ APTES solutions, in which the APTES concentration was the same.

It was checked that the APTES-based treatments produced polymer networks, as expected. A polymer network being insoluble in all solvents due to its infinite weight, the network formation was evaluated by measuring the soluble fraction amount extracted from the treated papers. Lower soluble fraction indicates better quality in the formation of the polymer network. The results of the polysiloxanes soluble fractions in dichloromethane are reported in Table 1.

The soluble fraction amount contained in polyAMDES treated paper was low (35 wt\%), the solubility of the linear polymer in dichloromethane being $100 \mathrm{wt} \%$. This result is in agreement with a previous study, which highlighted that the affinity of polyaminoalkylalkoxysilane for cellulose was affected via interactions between primary amine functions of siloxanes and hydroxyl groups of the cellulose (Souguir et al. 2011). As observed previously (Souguir et al. 2011), NMR ${ }^{1} \mathrm{H}$ analysis of the soluble fractions

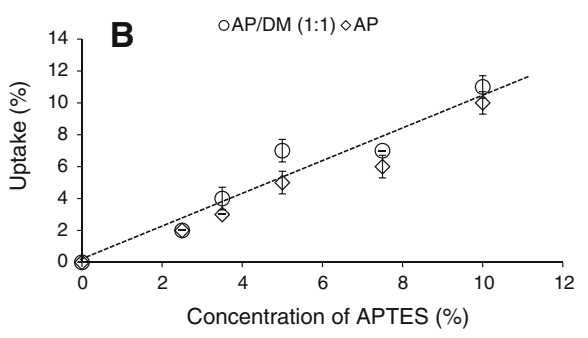

immersion in the solutions; $\mathbf{B}$ concentration of APTES for AP/ $\mathrm{DM}(1: 1)$ (white circle) and APTES (AP) (white diamond)

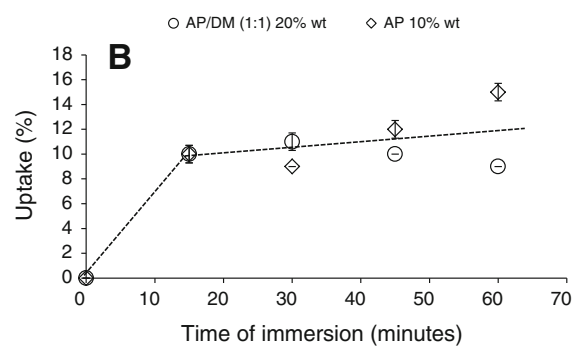

(AP/DM) at (white circle) $20 \mathrm{wt} \%$ and APTES (AP) (white diamond) $10 \mathrm{wt} \%$ in HMDS 
of polyAMDES extracted from the paper showed the characteristic peak of polyAMDES $\left(\delta_{\mathrm{D} 2 \mathrm{O}}\left(\mathbf{C H}_{3}-\mathrm{Si}\right)\right.$ : $0.02 \mathrm{ppm})$. No soluble fraction was obtained from polyAPTES treated paper $(0 \%)$. This result is consistent with the insolubility of the polyAPTES network. In other words, a polyAPTES network has formed in paper and cannot be extracted with dichloromethane. For polyAPTES/polyAMDES treatment, the soluble fraction ratio was also quite low (5 wt $\%$ ), which confirms the presence of a polymer network. The ${ }^{1} \mathrm{H}$ NMR analysis showed that the soluble fraction contains only linear polyAMDES. Finally, as for polyAPTES, the polyAPTES/polyDMDES treated paper contains no soluble fraction. This result corroborates the assumption made that DMDES evaporates before the formation of a copolymer network with APTES.

From these results one can conclude that a polysiloxane based network is synthesized in the paper when APTES is used as one of the precursors of the treatment. The physico-chemical properties of the treated papers were characterized next.

The concentrations and immersion durations selected for further study were $7 \mathrm{wt} \%$ and $45 \mathrm{~min}$ for APTES/ AMDES solution (uptake $=7 \%$ ), and $20 \mathrm{wt} \%$ and $30 \mathrm{~min}$ for APTES/DMDES solution (uptake $=8 \%$ ), respectively. Treatments with AMDES and APTES were chosen as reference for the physico-chemical properties and they were done at a concentration of $10 \mathrm{wt} \%$ in HMDS for $30 \mathrm{~min}$ as previously optimized (uptake $=6$ and $7 \%$, respectively) (Souguir et al. 2011). After treatment the samples were stored at constant conditions of temperature/humidity at $23{ }^{\circ} \mathrm{C}$ and $50 \% \mathrm{RH}$. It appears that the impregnation by spraying led to slightly higher uptakes than the impregnation by immersion, under the experimental conditions used. Although comparisons between the different treatments and methods of application would be easier if the uptakes had been comparable, this small difference was not considered undesirable as the main reason

Table 1 Soluble fraction amounts contained in the different papers after treatment (wt\%)

\begin{tabular}{lc}
\hline Treatment & SF (wt $)$ \\
\hline polyAMDES & 35 \\
polyAPTES & 0 \\
polyAPTES/polyAMDES & 5 \\
polyAPTES/polyDMDES & 0 \\
\hline
\end{tabular}

for testing the spray application was a practical one, i.e. to propose and study a solvent-free-and easy to use alternative treatment application.

Physico-chemical characterizations

\section{Opacity}

Opacity is an important factor to consider when designing a treatment for paper as problems of legibility in documents printed recto and verso can occur. The results of the opacity measurements are shown in Fig. 4. After the treatment with polyAMDES, a small loss of opacity was measured (17\% decrease $v s$ untreated P2). Conversely, the papers treated with polyAPTES displayed no opacity modification. Papers treated with polyAPTES/polyAMDES showed a smaller opacity loss than those treated with polyAMDES: $4 \%$ using the immersion application, and $9 \%$ using the spray application. For paper treated with polyAPTES/polyDMDES, no opacity loss was observed as the paper most likely contained mainly polyAPTES.

\section{Alkaline reserve}

Bringing an alkaline character to the paper is a significant feature of the multifunctional treatment developed. As it is an easier goal to achieve than the strengthening character, the efficiency of the deacidification was verified first. Results of the alkaline reserve measurements are gathered in Table 2.

The alkaline reserve values related to the number of moles of amine functions present. Alkaline reserve is

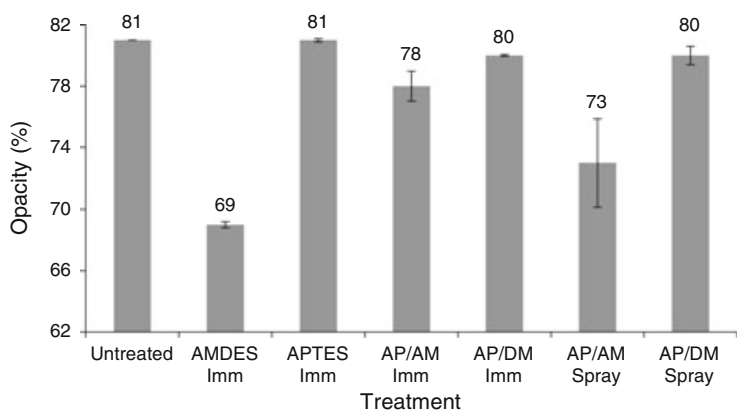

Fig. 4 Opacity of the papers untreated and treated with polyAMDES (AM), polyAPTES (AP), polyAPTES/polyAMDES (AP/AM) and (polyAPTES/polyDMDES) (AP/DM) by immersion (Imm) and spray 
Table 2 Alkaline reserve of the papers after the treatments
* $\left[\mathrm{NH}_{2}\right] / 100 \mathrm{~g}$ of paper $=52.6$ and 112 mmoles are maximum values assuming that no DMDES is present in the paper

\begin{tabular}{|c|c|c|c|}
\hline Treatment & $\begin{array}{l}\text { Alkaline } \\
\text { Reserve } \\
\left.\left(\mathrm{meq}^{-} \mathrm{OH}^{-}\right) / 100 \mathrm{~g}\right) \\
\pm \text { Standard } \\
\text { Deviation }\end{array}$ & $\begin{array}{l}\text { Uptake } \\
\text { (wt/wt \%) }\end{array}$ & $\begin{array}{l}{[\mathrm{NH} 2] / 100 \mathrm{~g}} \\
\text { of paper } \\
\text { (mmoles) }\end{array}$ \\
\hline \multicolumn{4}{|l|}{ Immersion } \\
\hline polyAMDESa & $33 \pm 1.06$ & 7 & 52.2 \\
\hline polyAPTES & $32 \pm 0.03$ & 7 & 52.6 \\
\hline polyAPTES/polyAMDES & $28 \pm 0.94$ & 6 & 44.9 \\
\hline polyAPTES/polyDMDES & $33 \pm 1.05$ & 7 & $52.6^{*}$ \\
\hline \multicolumn{4}{|l|}{ Spray } \\
\hline polyAPTES & $104 \pm 2.35$ & 19 & 142 \\
\hline polyAPTES/polyAMDES & $114 \pm 0.98$ & 21 & 157 \\
\hline polyAPTES/polyDMDES & $87 \pm 1.69$ & 15 & $\leq 112 *$ \\
\hline
\end{tabular}

seems that a small portion of DMDES is forced into the network when the spray process is used. This can be due to the fact that, contrary to an immersion treatment where chemical affinity can play a larger role, when sprayed the solutions are more or less forced to penetrate in the paper. However, as explained earlier, the largest part evaporates before reacting with APTES. The addition of polyAPTES/polyAMDES copolymers network in the paper mitigated the loss of opacity that was observed upon the AMDES treatment while maintaining a similar alkaline reserve.

\section{Mechanical strength}

Figure 6A shows the zsTS values of $\mathrm{P} 2$ as a function of the uptake for each impregnation process. All the treatments led to an improvement of the mechanical strength compared to untreated P2 (zsTS $=133 \mathrm{daN}$ $\mathrm{mm}^{-1}$ ). This indicates that inter-fiber and intra-fiber bonds of the cellulose fibers were strengthened by the presence of the polysiloxanes. Also, all the zsTS values obtained when polyAPTES was present (pure or in mixtures) were higher than those obtained after polyAMDES treatment $\left(\mathrm{zsTS}=141 \mathrm{daNmm}^{-1}\right)$, the latter value being consistent with previous results (Souguir et al. 2011). Whether by immersion or by spraying zsTS occurred between 148 and 153 daN$\mathrm{mm}^{-1}$, the higher values most often corresponding to the higher uptakes. This increase in the inter- and intra-fiber bonding energies of the cellulose fibers is most likely assignable to the formation of the polysiloxane network. Indeed, polymer networks generally show better mechanical properties than corresponding linear polymers (Klempner et al. 1994).

Fig. 5 Alkaline reserve as a function of the uptake 

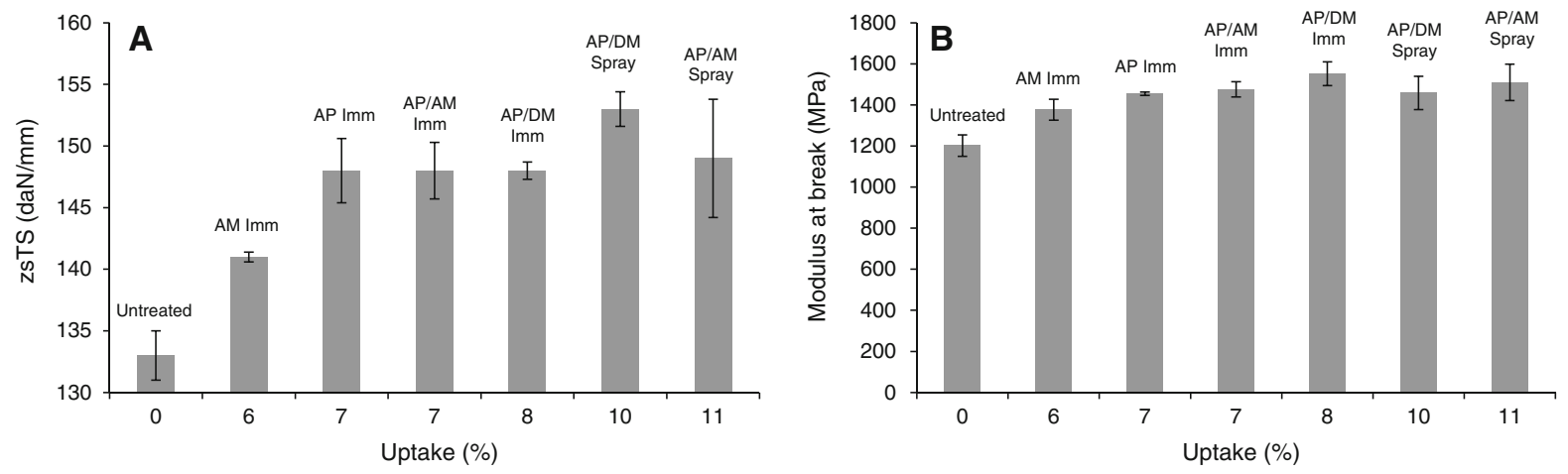

Fig. 6 A zsTS and B modulus at break of untreated and treated paper with polyAMDES (AM), polyAPTES (AP), polyAPTES/ polyAMDES (AP/AM) and polyAPTES/polyDMDES (AP/DM) applied by immersion (Imm) and spray

Beyond $7 \mathrm{wt} \%$ uptake zsTS seems to reach a plateau, indicating optimal inter-fiber and intra-fiber bond strengthening.

Figure 6B shows the tensile modulus of the papers depending on the uptake. Co-axial tensile strength correlates mostly with interfiber resistance. It can be seen that all the performed treatments increased the value of the modulus, thus the paper stiffness. This increase is consistent with the increase in zsTS. However, modulus is less influenced than zsTS by the differences in the uptake, and seems to have a somewhat stronger correlation with the treatment formulation.

The folding endurance of the treated papers is presented in Fig. 7. The measurements show an excellent reproducibility in most cases. The results show that all the papers, whether treated by immersion or by spray, undergo moderate (polyAMDES) to large (polyAPTES and its copolymers) improvement of their double fold resistance compared to untreated paper. This indicates a better deformation capacity and better plasticity (greater flexibility and deformability) of the paper after treatment, and confirms the results obtained previously with AMDES as well as with $3 \mathrm{~N}$ (2-aminoethyl)-3-aminopropylmethyl-dimethoxysilane (AEAPMDMS) (Souguir et al. 2011, 2012). Here again, the paper treated with polyAMDES was the least efficiently consolidated, which again was attributed to the formation of a linear polymer, less prone to inter-connect the cellulose fibers than a network. The FE of the samples treated by spray was slightly better than that of the samples treated by immersion, which has to do with the respective uptakes, as mentioned earlier. With uptakes from 6 to $8 \%$, the FE improvement after the immersion treatment ranged from 24 to $35 \%$ compared to the untreated paper. With uptakes in the range 10-11\% upon spraying, the improvement reached up to $59 \%$ in the case of polyAPTES/polyAMDES treatment. The data also shows that folding endurance of the paper seems more dependent on small differences in uptake than zsTS. Indeed, FE shows a stronger linear correlation with the uptake (see Supplementary Material file).

The results also indicate that the polyAPTES/ polyAMDES treatment was more efficient than polyAPTES/polyDMDES. The former network thus seems to function better as strengthening agent than the latter. As explained earlier, AMDES and DMDES were included in the mixtures to provide flexibility to the pure polyAPTES network. However, DMDES does not seem to play this role, which is consistent with the hampered penetration of DMDES in the paper as proposed earlier.

The mechanical tests show that the different treatments reproducibly consolidated the paper to different extents, i.e. they all result in an increase of the fiber resistance and of the plasticity of the material. According to the results taken globally using a pure cotton paper, the two treatments polyAPTES/polyAMDES and polyAPTES stand out as strengthening agents of cellulosic fibers compared to the other treatments.

\section{Contact angle}

The influence of the different treatments on the wetting properties of the paper was investigated by measuring the contact angles (Table 3). 


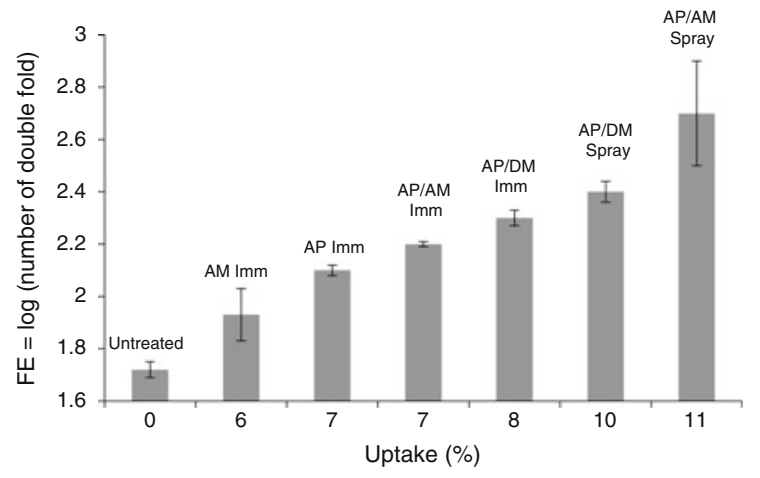

Fig. 7 FE measurements for untreated and treated paper with polyAMDES (AM), polyAPTES (AP), polyAPTES/polyAMDES (AP/AM) and polyAPTES/polyDMDES (AP/DM) applied by immersion (Imm) and spray

Table 3 Contact angle of a water drop on papers treated and untreated

\begin{tabular}{ll}
\hline Treatment & Contact angle \\
\hline Immersion & \\
polyAMDES & Not measurable \\
polyAPTES & $98^{\circ}$ \\
polyAPTES/polyAMDES & Not measurable \\
polyAPTES/polyDMDES & $115^{\circ}$ \\
Spray & \\
polyAPTES/polyAMDES & Not measurable \\
polyAPTES/polyDMDES & $102^{\circ}$ \\
\hline
\end{tabular}

For untreated paper, the contact angle could not be measured as the water drop was instantly absorbed (Table 3). This was expected as P2 paper does not contain any sizing, coating or finish material. The contact angle values depend on the treatment composition, but, for each particular treatment, they were similar with either application process, immersion or spray. For paper treated with polyAMDES, the water drop spread slowly over time and was eventually absorbed. The contact angle measurement could thus not be achieved. Conversely, with polyAPTES treatment, the water drop did not spread and was still not absorbed after several minutes. The contact angle was $98^{\circ}$. Thus the polyAPTES treatment provides a hydrophobic character to the paper. For polyAPTES/ polyAMDES treatment, the water drop spread slower than with polyAMDES but a contact angle was still not measurable. In theory, polyAPTES/polyAMDES network is less dense than polyAPTES. Moreover, with a contact angle of $115^{\circ}$, the contact angle on polyAPTES/polyDMDES treated paper was very similar to that of polyAPTES treated paper, which again corroborates the hypothesis on the non-absorption of DMDES.

The increase in hydrophobicity of the paper after treatment is consistent with the fact that the amine functions would be oriented towards the cellulose fibers as previously hypothesized, while the silicone moiety of the polymer would be oriented outward. This is yet another interesting feature for historic papers as reducing the hydrophilic character of paper has several advantages, among which a better resistance to water spills (e.g. floods) and a slowed moisture exchange rate with the environment, which in turn will slower the natural degradation rate with time (du Plooy 1981; Feller 1994; Welf et al. 2005; Havlínová et al. 2009).

\section{Conclusion}

Building on previous research endeavours that were devoted to developing a treatment for the simultaneous deacidification and reinforcement of degraded paper upon incorporation of a single aminoalkylakoxysilane, this work has shown that it was possible to achieve equal or more efficient reinforcement by impregnating the paper with a mixture of two differently functionalised polysiloxanes. The combination of an aminotrialkoxysilane (APTES) with an aminodialkoxysilane (AMDES) effectively led to the formation of a copolymer network in the paper as shown upon quantifying and characterizing the soluble fractions contained in the treated papers. Through random distribution of linear polyAMDES segments into a polyAPTES network it was possible to achieve a network less compact and thus more suitable for paper material than a single polyAPTES network. This copolymer network was more efficient than a simple linear polyAMDES impregnation, as shown by the modification of the mechanical properties of the paper. The deacidification efficiency was established and the treatment induced minimal loss of opacity, smaller than using polyAMDES alone. Moreover, the paper treated with polyAPTES/polyAMDES showed a decrease in hydrophilic character, a feature that is of interest to the long-term stability of cellulosic material. The impregnation with the treatment molecules 
using a spray, a desirable application mode because of its ease of application and solvent-free process was successful, bringing results that were fully comparable to the results of an immersion treatment in dilute solutions.

The purpose of this research was to achieve the formation of copolymer networks in the paper, in view of the future application to the treatment of very degraded paper such as newsprint collections. From this perspective and to simplify the number of experimental variables linked to the material, the experiments were carried out on good quality nondegraded model paper. Future research will be devoted to the study of the reinforcement by copolymer networks of degraded paper using artificially aged model papers as well as real old newsprint collections.

Acknowledgments We thank the PATRIMA Foundation for Camille Piovesan's research grant (CoMPresSil project). Sabrina Paris from CRCC is warmly thanked for technical assistance.

\section{References}

Baty JW, Maitland CL, Minter W, Hubbe MA, Jordan-Mowery SK (2010) Deacidification for the conservation and preservation of paper-based works: a review. BioResources 5(3):1955-2023

Carter HA (1996) The chemistry of paper preservation: part 1. the aging of paper and conservation techniques. J Chem Educ 73(5):417-420

Du Plooy A (1981) The influence of moisture content and temperature on aging rate of paper. Appita J 34(4):287-292

Dupont A-L, Lavedrine B, Cheradame H (2010) Mass deacidification and reinforcement of papers and books VI. Study of aminopropylmethyldiethoxysilane treated papers. Polym Degrad Stab 95:2300-2308
Feller RL (1994) Accelerated aging photochemical and thermal aspects. The effect of moisture in oxidative degradation, Research in Conservation series Getty Conservation Institute, pp 115-128

Havlínová B, Katusščcák S, Petrovičová M, Maková A, Brezová V (2009) A study of mechanical properties of papers exposed to various methods of accelerated ageing. Part I. The effect of heat and humidity on original wood-pulp papers. J Cult Herit 10:222-231

Ipert S, Rousset E, Cheradame H (2005) Mass deacidification of papers and books III: study of a paper strengthening process and deacidification process with amino alkyl alkoxy silanes. Restaur Int J Preserv Lib Archival Mater 26:250-264

Ipert S, Dupont A-L, Lavedrine B, Begin P, Rousset E, Cheradame H (2006) Mass deacidification of papers and books. IV: a study of papers treated with aminoalkylalkoxysilanes and their resistance to ageing. Polym Degrad Stab 9:3448-3455

Klempner D, Sperling LH, Utracki LA (1994) Interpenetrating polymer networks. Adv Chem Ser 239:3-123

Porck H (1996) Mass deacidification: an update on possibilities and limitations. European Commission on Preservation and Access, Amsterdam, p 54

Rakotonirainy MS, Dupont A-L, Lavedrine B, Ipert S, Cheradame H (2008) Mass deacidification of papers and books: V. Fungistatic properties of papers treated with aminoalkylalcoxysilanes. J Cult Herit 9:54-59

Souguir Z, Dupont A-L, d'Espinose de Lacaillerie J-B, Lavedrine B, Cheradame H (2011) Chemical and physicochemical investigation of an Aminoalkylalkoxysilane As strengthening agent for cellulosic materials. Biomacromolecules 12:2082-2091

Souguir Z, Dupont A-L, Fatyeyeva K, Mortha G, Cheradame H, Ipert S, Lavedrine B (2012) Strengthening of degraded cellulosic material using a diamine alkylalkoxysilane. RSC Adv 2:7470-7478

Welf ES, Venditti RA, Hubbe MA, Pawlak JJ (2005) The effects of heating without water removal and drying on the swelling as measured by water retention value and degradation as measured by intrinsic viscosity of cellulose papermaking fibers. Prog Pap Recycl 14(3):1-9 